\title{
Correction to: Effects of Zn Additions \\ on the Room Temperature Formability \\ and Strength in $\mathrm{Mg}-1.2 \mathrm{Al}-0.5 \mathrm{Ca}-0.4 \mathrm{Mn}$ \\ Alloy Sheets
}

Z. H. Li, T. T. Sasaki, M. Z. Bian, T. Nakata, Y. Yoshida, N. Kawabe,

S. Kamado, and K. Hono

\section{Correction to:}

Chapter "Effects of Zn Additions on the Room Temperature Formability and Strength in Mg-1.2Al-0.5Ca-0.4Mn Alloy Sheets" in: J. B. Jordon et al. (eds.), Magnesium Technology 2020, The Minerals, Metals \& Materials Series, https://doi.org/10.1007/978-3-030-36647-6_18

The original version of this chapter was inadvertently published with incorrect Figure.

Author provided figure corrections has been updated: Figure 4 has been removed and remaining figures are renumbered.

The Chapter and book have been updated with the changes. 